\title{
Shining a Light on the Effects of the Combination of (-)-Epigallocatechin-3-gallate and Tapentadol on the Growth of Human Triple-negative Breast Cancer Cells
}

\author{
SABRINA BIMONTE ${ }^{1 *}$, MARCO CASCELLA $^{1 *}$, ANTONIO BARBIERI $^{2 *}$, \\ CLAUDIO ARRA $^{2}$ and ARTURO CUOMO ${ }^{1}$ \\ ${ }^{1}$ Division of Anesthesia and Pain Medicine, National Institute of Tumors, G. Pascale Foundation, Naples, Italy; \\ ${ }^{2}$ S.S.D Animal Experimentation, National Institute of Tumors, G. Pascale Foundation, Naples, Italy
}

\begin{abstract}
Background/Aim: Breast cancer is characterized by a high rate of mortality and is considered one of the deadliest types of cancer. It is of note that (-)epigallocatechin-3-gallate (EGCG), the principal catechin of green tea, is able to hinder the growth of MDA-MB-231 breast cancer cells by influencing different signaling pathways, including apoptosis. Furthermore, EGCG is also used in the treatment of bone cancer pain. Tapentadol, an opioid drug acting at the level of noradrenaline (norepinephrine) reuptake inhibition and $\mu$-opioid receptor, is able to modulate bone cancer pain and influence cancer cell viability by regulating apoptosis. Materials and Methods: In vitro assays were performed on triple-negative MDA-MB-231 cells treated with tapentadol $(1,5,10,20,40$ and $80 \mu \mathrm{g} / \mathrm{ml})$ and EGCG $(1,10$, $20,40,80,160 \mu \mathrm{mol} / \mathrm{l})$, alone and in combination. The effects of EGCG and TAP on viability were determined by woundhealing and MTT assays, while cell migration was assessed by transwell migration. Results: Cell proliferation, viability and apoptosis of MDA-MB-231 cells were impaired by the combination of EGCG and tapentadol. Specifically, our data show that EGCG and TAP reduced the proliferation of MDA$M B-231$ cells by impairing cell-cycle progression $(p<0.05)$. These findings suggest that the combination of these substances may represent a new strategy for the treatment of patients suffering from triple-negative breast cancer.
\end{abstract}

This article is freely accessible online.

*These Authors contributed equally to this study.

Correspondence to: Sabrina Bimonte, Division of Anesthesia and Pain Medicine, Istituto Nazionale Tumori, IRCCS Fondazione G. Pascale, Naples, Italy. E-mail: s.bimonte@istitutotumori.na.it

Key Words: (-)-Epigallocatechin-3-gallate, tapentadol, triplenegative breast cancer, cell proliferation, apoptosis.
Breast cancer, the second cause of cancer death for women worldwide $(1,2)$, is considered a heterogeneous disease, mainly at locally advanced stages (3). To date, many therapies for breast cancer have been proposed and recent ones have been identified as targeted treatments $(4,5)$, being based on a profile of positive estrogen receptor (ER) expression, which is considered one of the predictive markers for breast cancer. Unfortunately, these therapies cannot be successfully applied to patients with triplenegative breast cancer (TNBC) or ER-negative cancer, indicating an urgent need for alternative strategies for breast cancer treatment for such patients. Several studies have shed light on new possible therapeutic approaches for breast cancer management, based on the combination of natural compounds with conventional drugs $(6,7)$. (-)Epigallocatechin gallate (EGCG), the main catechin of green tea (8-11), is able to inhibit tumor progression in several types of cancer (12-15), such as breast cancer (10, $16,17)$, due to its antioxidant and anti-inflammatory properties $(18,19)$.

EGCG was shown to reduce breast tumorigenesis by modulating the expression of p53 and BCL2-associated X protein (BAX) and the activation of caspase-3 (17). Recently Hong et al. showed that EGCG regulated breast cancer progression by inactivating the canonical $\beta$-catenin signaling pathway (20). Regarding opiate-based drugs in breast cancer treatment, we and others have shown that morphine was able to modulate breast cancer growth and progression by acting with opposing effects and on different molecular pathways as a consequence of its dosage (21-23). Another opioid drug, which, like morphine, is commonly used in pain treatment, is tapentadol (24). To date, an effect of tapentadol on cancer cell proliferation has been shown only for the SH-SY5Y neuroblastoma cell line (25). Since EGCG and tapentadol are able to affect cancer cell proliferation via apoptosis, we studied the effects of their combination on MDA-MB-231 cells. 

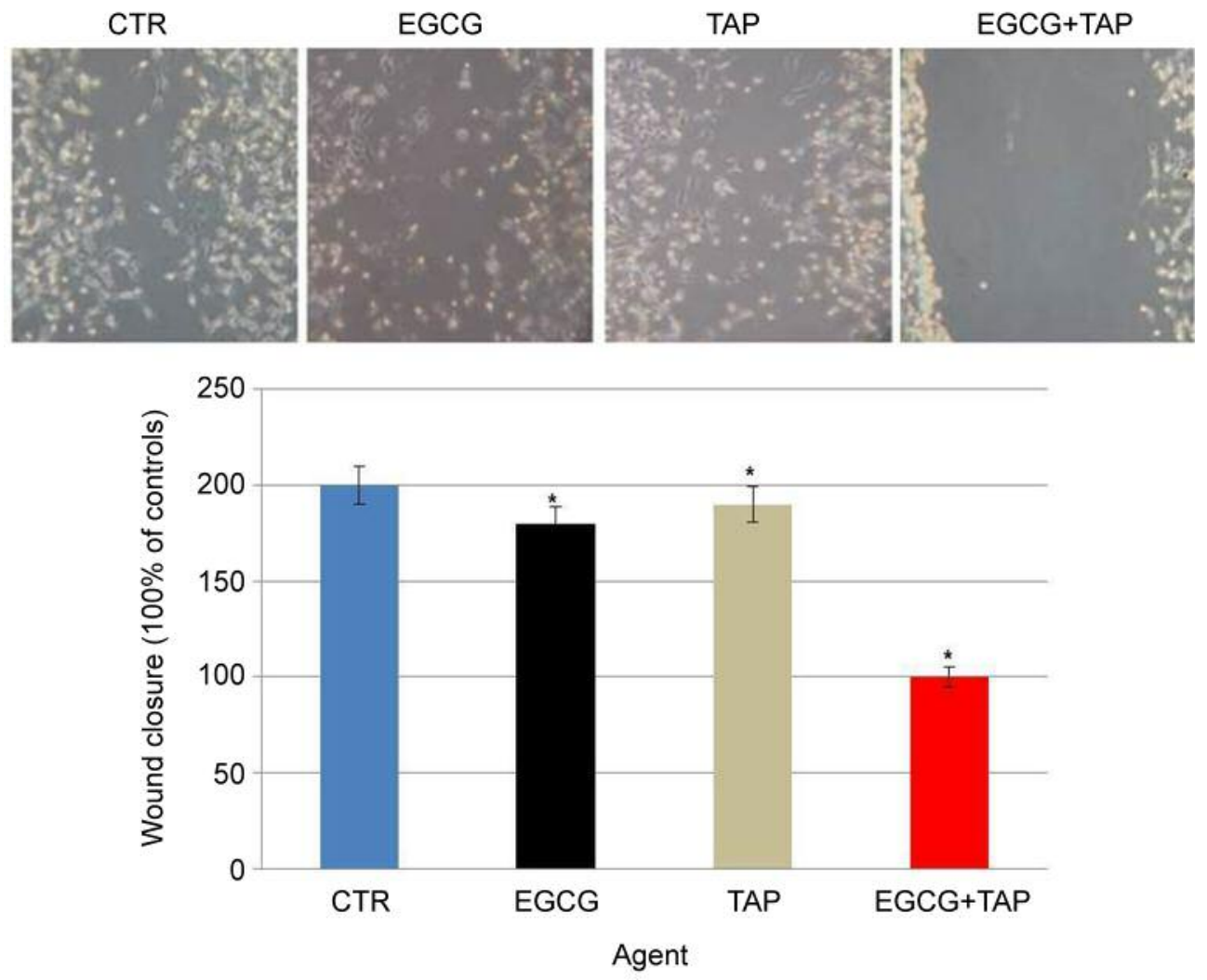

Figure 1. Effects of (-)-epigallocatechin-3-gallate (EGCG) and tapentadol (TAP) on migration of MDA-MB-231 cells. MDA-MB-231 cells were

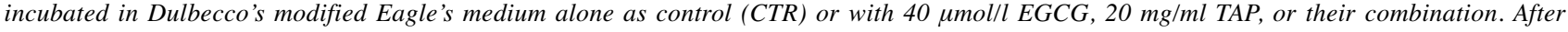
$48 \mathrm{~h}$, the inhibitory effect of the two substances was clearly evident with respect to single substances and to controls. Values are the means $\pm S E$ for three independent experiments. *Significantly different from the control at $p<0.05$.

\section{Materials and Methods}

Materials. Tapentadol hydrochloride was obtained by Grünenthal (Aquisgrana, Germany). Different doses of tapentadol (1, 5, 10, 20, 40 and $80 \mathrm{mg} / \mathrm{ml})$ and EGCG $(1,10,20,40,80,160 \mu \mathrm{M})$ were employed for in vitro experiments on MDA-MB-231 cells. EGCG was purchased from Sigma. Antibody to p53 was purchased from Imgenex (San Diego, CA, USA). 3,3-Diaminobenzidine, antibiotics (penicillin and streptomycin), Dulbecco's modified Eagle's medium (DMEM), and fetal bovine serum were purchased from Invitrogen (Grand Island, NY, USA). Hydroxymethyl (Tris), glycine, sodium chloride $(\mathrm{NaCl})$, sodium dodecyl sulfate (SDS), and bovine serum albumin were purchased from Sigma Chemical (St. Louis, MO, USA). Antibodies to $\mathrm{p} 53$, cyclin D1, and anti-actin were obtained by Imgenex (San Diego, CA, USA).

Cell culture. The human ER-negative breast cancer cell line MDAMB-231 was purchased from the American Type Culture Collection (ATCC Manassas, VA, USA). Cells were cultured in DMEM (Invitrogen) supplemented with antibiotics (penicillin $100 \mathrm{U} / \mathrm{ml}$; streptomycin $100 \mathrm{U} / \mathrm{ml}), 10 \%$ heat-inactivated fetal bovine serum, and L-glutamine $(2 \mathrm{mmol} / \mathrm{l})$ in a humidified atmosphere at $37^{\circ} \mathrm{C}$. Wound-healing assay. The assay was performed as previously described (21) to test the migration of MDA-MB-231 cells ( 70$80 \%$ confluence as a monolayer and at density of $\left.0.3 \times 10^{6}\right)$.
Proliferation assay. The effect of EGCG and tapentadol on cell proliferation was determined by using the 3-(4,5-dimethylthiazol-2yl)-2,5-diphenyltetrazolium bromide (MTT) cell proliferation assay (Trevigen, Gaithersburg, MD, USA), as reported by Bimonte et al. (21). The cells ( $70-80 \%$ confluence as a monolayer) were incubated at density of $2 \times 10^{3}$ per well.

Cell invasion. MDA-MB-231 cells $\left(5 \times 10^{4}\right.$ of density and $\sim 70-80 \%$ confluence as a monolayer) were cultured in DMEM and cell invasion was performed as described by Justus et al. (26).

In vitro apoptosis assay by flow cytometry. Cells were washed and suspended in $0.5 \mathrm{ml}$ of phosphate-buffered saline, fluorescein isothiocyanate-dextran, annexin $\mathrm{V}$ and propidium iodide (PI). The in vitro assay was performed as described by Bimonte et al. (15).

Cell-cycle analysis. The cells were seeded at $3 \times 10^{5}$ cells per well into 6-well plates and incubated overnight at $37^{\circ} \mathrm{C}$ in a $\mathrm{CO}_{2}$ incubator (15). The cells were then washed with phosphatebuffered saline and treated with medium as control or with EGCG $(40 \mu \mathrm{M})$, tapentadol $(20 \mathrm{mg} / \mathrm{ml})$, or their combinations (40 $\mu \mathrm{M}$ EGCG plus $20 \mathrm{mg} / \mathrm{ml}$ tapentadol), and incubated for 24 and $48 \mathrm{~h}$. Analysis was performed as described by Bimonte et al. (15). 


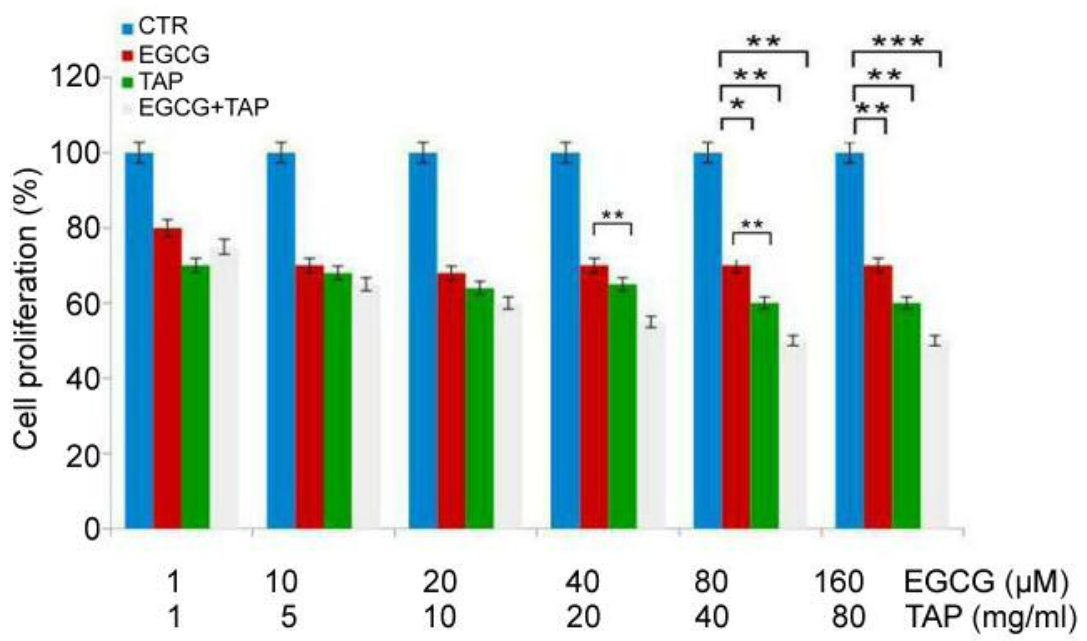

Figure 2. (-)-Epigallocatechin-3-gallate (EGCG) and tapentadol (TAP) inhibit the proliferation of MDA-MB-231 cells. MTT assay showed a dosedependent inhibition of the viability of cells treated for $48 \mathrm{~h}$ with $40 \mu \mathrm{mol} / \mathrm{l}$ EGCG or with $20 \mathrm{mg} / \mathrm{ml}$ TAP, or their combination and TAP. A stronger effect was observed using the combined treatment. Values are the means \pm SE for three independent experiments. Significantly different at concentration of 40, 80 and $160 \mu \mathrm{M}$ for EGCG and 20,40 and $80 \mathrm{mg} / \mathrm{ml}$ for TAP*p<0.05, ** $p<0.01$ and ***p<0.001 by analysis of variance.

Table I. Analysis of cell-cycle distribution of MDA-MB-231 cells treated with (-) epigallocatechin-3-gallate (EGCG), tapentadol (TAP), and both agents together.

\begin{tabular}{lcrc}
\hline & \multicolumn{3}{c}{ Cell-cycle distribution (\%) } \\
\cline { 2 - 4 } Treatment & $\mathrm{G}_{0} / \mathrm{G}_{1}$ & $\mathrm{~S}$ & $\mathrm{G}_{2} / \mathrm{M}$ \\
\hline Control & 61 & 12 & 24 \\
DMSO & 62 & 12 & 24 \\
$40 \mu \mathrm{M}$ EGCG & 40 & 26 & 26 \\
$20 \mu \mathrm{M}$ TAP & 63 & 9 & 21 \\
$40 \mu \mathrm{M}$ EGCG plus $20 \mu \mathrm{M}$ TAP & 49 & 10 & 20 \\
\hline
\end{tabular}

DMSO: Dimethyl sulfoxide.

Statistical analysis. Data were analyzed by using one-way analysis of variance (ANOVA) test and expressed as the mean values of at least three independent replications $(p<0.05)$.

\section{Results}

The effects of EGCG and tapentadol on the migration and the proliferation of $M D A-M B-231$ cells. A wound-healing assay was performed to assess the effects of EGCG and tapentadol on MDA-MB-231 cell migration. The data showed that EGCG and tapentadol alone retarded the migration of MDA-MB-231 cells at $48 \mathrm{~h}(p<0.05)$. The effect was significantly potentiated when the substances were combined $(p<0.05)$ (Figure 1). We assessed whether EGCG and tapentadol is able to inhibit the proliferation of MDAMB-231 cells by performing an MTT assay. A reduction in

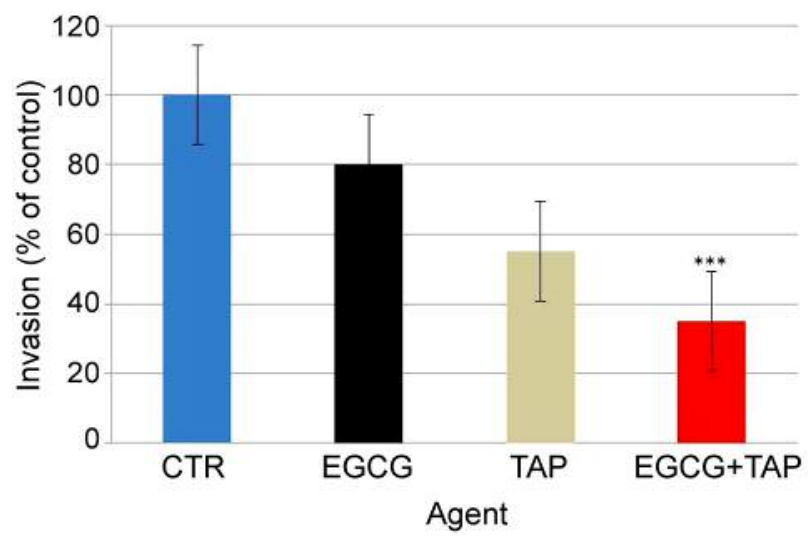

Figure 3. (-)-Epigallocatechin-3-gallate (EGCG) and tapentadol (TAP) are able to inhibit the invasion of MDA-MB-231 cells at $48 \mathrm{~h}$. A stronger effect was observed in all groups of treatment *** Significantly different compared with control at $p<0.001$ by analysis of variance. Values are the means $\pm S E$ for three independent experiments.

cellular proliferation after $48 \mathrm{~h}$ of treatment with all combinations was observed, as reported in Figure 2.

Data obtained by the invasion test showed that treatment with EGCG plus tapentadol effectively inhibited migration of MDA-MB-231 cells, which was less than those of MDAMB-231 cells treated with single substances and controls without substances (Figure 3; $p<0.0001$ ).

Our results show that EGCG and tapentadol reduced the proliferation and the invasion of MDA-MB-231 at high doses, thus suggesting that toxicity may have caused cell death. 


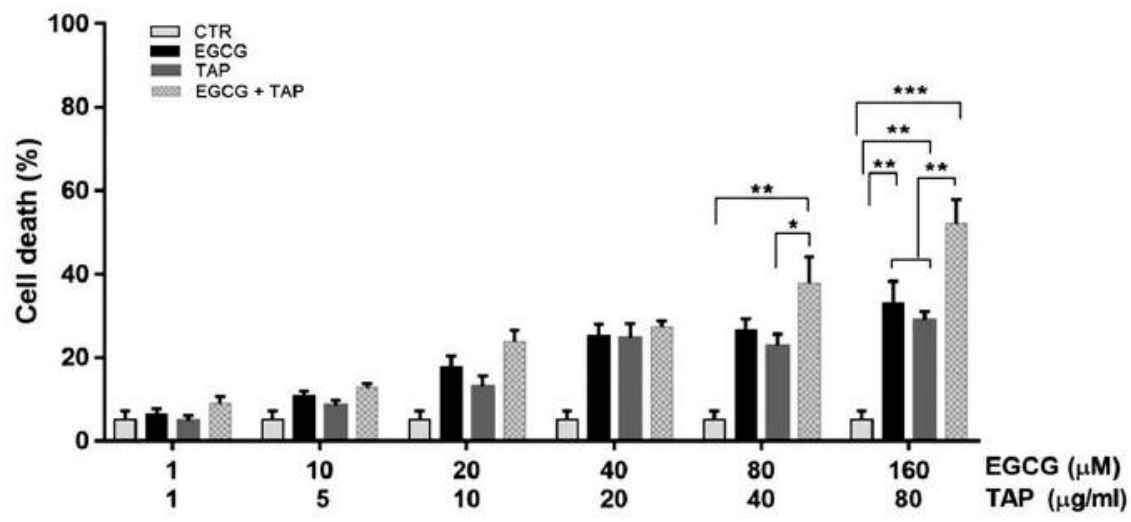

Figure 4. The effects of (-)-epigallocatechin-3-gallate (EGCG) and tapentadol (TAP) on apoptosis of MDA-MB-231 cells. In vitro apoptosis assay by flow cytometry showed the effect of the substances alone as control (CTR), and with EGCG, TAP and their combination on apoptosis of MDAMB-231 cells. An enhancement of apoptosis was observed with the combination of both compounds. Values for means \pm SE for three independent experiments. Significantly different at $* p<0.05, * * p<0.01$ and $* * * p<0.001$ by analysis of variance.

The effects of EGCG and tapentadol on MDA-MB-231 cell apoptosis and cell-cycle progression. Flow cytometry was also performed to test the apoptosis of MDA-MB-231 cells treated with EGCG alone, tapentadol alone and both substances combined. Data showed that the percentage of cell death was higher in the group treated with combinations compared with respect to that observed in the groups with single treatment (Figure 4 and Table I).

\section{Discussion}

Our experimental in vitro studies highlighted findings on the effects of EGCG and tapentadol on TNBC cell growth. It is of note that conventional therapies adopted to treat patients with ER-positive breast cancer cannot be successfully applied to patients with ER-negative or TNBC due to the lack of expression of ER, progesterone receptor, or human epidermal growth factor receptor type 2, thus suggesting an urgent need for alternative strategies for treatment of patients with breast cancer. Several studies shed light on new possible therapeutic approaches for breast cancer management, based on the combination of natural compounds and conventional drugs. EGCG is able to regulate breast cancer progression by inducing the apoptosis and by inhibiting cell cycle progression (27). On the basis of the results obtained by using morphine on MDA-MB-231 cells, we decided to select the TAP as alternative opioids to morphine in vitro experiments on MDA-MB-231 cells. Here we evaluated the efficacy and synergism of EGCG and tapentadol against breast cancer cells. Our findings indicate that the combination of EGCG and tapentadol potentiates the antiproliferative effects of the single substances by apoptosis induction in MDA-MB-231 cells and by affecting cell-cycle progression. It is important to underline that refinement of experiments performed in further breast cancer cell lines are desperately needed to set out the precise in vitro dosages of both substances, in order to be translated into in vivo animal models.

Several points can be extrapolated from the results of these in vivo studies in order to translate findings to clinical practice. For instance, although in our experiments, the effect of the combined treatments showed synergistic effects, significant inhibition of migration, proliferation and cellcycle progression in MDA-MB-231 cells, was observed supra-physiological at concentrations. Consequently, other experiments conducted using different concentrations are needed in order to make it possible to translate our results into clinical practice. Furthermore, because tapentadol acts on mu-opioid receptors (MORs) it should be investigated whether or not MDA-MB-231 cells express MORs. In addition, another point of discussion regards the possibility that MORs are implicated in the cytotoxic effect. On these bases, the potential effects of EGCG (regulation/modulation) on MOR expression should be better studied, thus other studies should be conducted in order to explain the mechanisms underlying our results.

\section{Conclusion}

Our data suggest that EGCG and tapentadol reduced the proliferation of MDA-MB-231 cells by inhibiting the progression of the cell cycle. This combination could be viewed as a new positive strategy for TNBC treatment. To our knowledge, this is a unique report of the combinatorial inhibitory effect of EGCG and tapentadol on MDA-MB-231 cancer cell growth. More experiments are needed to elucidate the signaling pathways in the regulation of growth of breast cancer cells affected by EGCG and tapentadol. 


\section{Funding}

This work was supported by a research project of National Cancer Institute of Naples, IRCCS G. Pascale Foundation (grant no. M3/3, principal investigator Dr. Sabrina Bimonte).

\section{Authors' Contributions}

$\mathrm{BS}, \mathrm{MC}$ and $\mathrm{AB}$ are the main authors of the study. $\mathrm{AC}$ and $\mathrm{CA}$ were responsible for the coordination of this study. All Authors read and approved the final article.

\section{Conflicts of Interest}

The Authors declare that they have no competing interests in regard to this study.

\section{Acknowledgements}

The Authors are grateful to Dr. Alessandra Trocino, Mrs. Cristina Romano from the National Cancer Institute of Naples, IRCCS Fondazione G. Pascale, for providing excellent bibliographic service and informatics assistance. We are grateful to Dr. Antonio Luciano and Dr. Giuseppe Palma from the National Cancer Institute of Naples, IRCCS G. Pascale Foundation, for providing technical assistance in experiments.

\section{References}

1 Parkin DM, Bray F, Ferlay $\mathrm{J}$ and Pisani P: Global cancer statistics, 2002. CA Cancer J Clin 55(2): 74-108, 2005. PMID: 15761078 .

2 Ferlay J, Soerjomataram I, Dikshit R, Eser S, Mathers C, Rebelo M, Parkin DM, Forman D and Bray F: Cancer incidence and mortality worldwide: sources, methods and major patterns in GLOBOCAN 2012. Int J Cancer 136(5): E359-386, 2015. PMID: 25220842. DOI: $10.1002 /$ ijc. 29210

3 Perou CM, Sørlie T, Eisen MB, van de Rijn M, Jeffrey SS, Rees CA, Pollack JR, Ross DT, Johnsen H, Akslen LA, Fluge O, Pergamenschikov A, Williams C, Zhu SX, Lønning PE, Børresen-Dale AL, Brown PO and Botstein D: Molecular portraits of human breast tumours. Nature 406(6797): 747-752, 2000. PMID: 10963602. DOI: 10.1038/35021093

4 Gadducci A, Biglia N, Sismondi P and Genazzani AR: Breast cancer and sex steroids: critical review of epidemiological, experimental and clinical investigations on etiopathogenesis, chemoprevention and endocrine treatment of breast cancer. Gynecol Endocrinol 20(6): 343-360, 2005. PMID: 16019385. DOI: $10.1080 / 09513590500128492$

5 Piccart-Gebhart MJ, Procter M, Leyland-Jones B, Goldhirsch A, Untch M, Smith I, Gianni L, Baselga J, Bell R, Jackisch C, Cameron D, Dowsett M, Barrios CH, Steger G, Huang CS, Andersson M, Inbar M, Lichinitser M, Láng I, Nitz U, Iwata H, Thomssen C, Lohrisch C, Suter TM, Rüschoff J, Suto T, Greatorex V, Ward C, Straehle C, McFadden E, Dolci MS, Gelber RD and Herceptin Adjuvant (HERA) Trial Study Team: Trastuzumab after adjuvant chemotherapy in HER2-positive breast cancer. N Engl J Med 353(16): 1659-1672, 2005. PMID: 16236737. DOI: 10.1056/NEJMoa052306
6 Sartippour MR, Pietras R, Marquez-Garban DC, Chen HW, Heber D, Henning SM, Sartippour G, Zhang L, Lu M, Weinberg O, Rao JY and Brooks MN: The combination of green tea and tamoxifen is effective against breast cancer. Carcinogenesis 27(12): 24242433, 2006. PMID: 16785249. DOI: $10.1093 /$ carcin/bg1066

7 Sak K: Chemotherapy and dietary phytochemical agents: Chemother Res Pract 2012: 282570, 2012. PMID: 23320169.

8 Nakachi K, Matsuyama S, Miyake S, Suganuma M and Imai K: Preventive effects of drinking green tea on cancer and cardiovascular disease: epidemiological evidence for multiple targeting prevention. BioFactors 13(1-4): 49-54, 2000. PMID: 11237198.

9 Kurahashi N, Sasazuki S, Iwasaki MInoue M, Tsugane S and JPHC Study Group: Green tea consumption and prostate cancer risk in Japanese men: a prospective study. Am J Epidemiol 167(1): 71-77, 2008. PMID: 17906295. DOI: 10.1093/aje/ kwm249

10 Yang CS, Landau JM, Huang MT and Newmark HL: Inhibition of carcinogenesis by dietary polyphenolic compounds. Annu Rev Nutr 21(1): 381-406, 2001. PMID: 11375442. DOI: 10.1146/ annurev.nutr.21.1.381

11 Zhang M, Holman CDAJ, Huang JP and Xie X: Green tea and the prevention of breast cancer: a case-control study in Southeast China. Carcinogenesis 28(5): 1074-1078, 2007. PMID: 17183063. DOI: $10.1093 /$ carcin/bg1252

12 Khan N, Afaq F, Saleem M, Ahmad N and Mukhtar H: Targeting multiple signaling pathways by green tea polyphenol (-)epigallocatechin-3-gallate. Cancer Res 66(5): 2500-2505, 2006. PMID: 16510563. DOI: 10.1158/0008-5472.CAN-05-3636

13 Stuart EC, Scandlyn MJ and Rosengren RJ: Role of epigallocatechin gallate (EGCG) in the treatment of breast and prostate cancer. Life Sci 79(25): 2329-2336, 2006. PMID: 16945390. DOI: $10.1016 / j .1 f s .2006 .07 .036$

14 Bimonte S, Cascella M, Leongito M, Palaia R, Caliendo D, Izzo $\mathrm{F}$ and Cuomo A: An overview of pre-clinical studies on the effects of (-)-epigallocatechin-3-gallate, a catechin found in green tea, in treatment of pancreatic cancer. Recenti Prog Med 108(6): 282287, 2017. PMID: 28631776. DOI: 10.1701/2715. 27715

15 Bimonte S, Leongito M, Barbieri A, Del Vecchio V, Barbieri M, Albino V, Piccirillo M, Amore A, Di Giacomo R, Nasto A, Granata V, Petrillo A, Arra C and Izzo F: Inhibitory effect of (-)epigallocatechin-3-gallate and bleomycin on human pancreatic cancer MiaPaca-2 cell growth. Infect Agent Cancer 10: 22, 2015. PMID: 26225138. DOI: 10.1186/s13027-015-0016-y

16 Thangapazham RL, Singh AK, Sharma A, Warren J, Gaddipati JP and Maheshwari RK: Green tea polyphenols and its constituent epigallocatechin gallate inhibits proliferation of human breast cancer cells in vitro and in vivo. Cancer Lett 245(1): 232-241, 2007. PMID: 16519995. DOI: 10.1016/ j.canlet.2006.01.027

17 Roy AM, Baliga MS and Katiyar SK: Epigallocatechin-3-gallate induces apoptosis in estrogen receptor-negative human breast carcinoma cells via modulation in protein expression of p53 and Bax and caspase-3 activation. Mol Cancer Ther 4(1): 81-90, 2005. PMID: 15657356.

18 Cascella M, Bimonte S, Muzio MR, Schiavone V and Cuomo A: The efficacy of epigallocatechin-3-gallate (green tea) in the treatment of Alzheimer's disease: an overview of pre-clinical studies and translational perspectives in clinical practice. Infect Agent Cancer 12: 36, 2017. PMID: 2864280. DOI: 10.1186/ s13027-017-0145-6 
19 Yang C and Wang H: Cancer preventive activities of tea catechins. Molecules 21(12): 1679, 2016. PMID: 27941682. DOI:10.3390/molecules21121679

20 Hong OY, Noh EM, Jang HY, Lee YR, Lee BK, Jung SH, Kim and Youn HJ: Epigallocatechin gallate inhibits the growth of MDA-MB-231 breast cancer cells via inactivation of the $\beta$ catenin signaling pathway. Oncol Lett 14(1): 441-446, 2017. PMID: 2869318. DOI:10.3892/ol.2017.6108

21 Bimonte S, Barbieri A, Rea D, Palma G, Luciano A, Cuomo A, Arra $\mathrm{C}$ and Izzo F: Morphine promotes tumor angiogenesis and increases breast cancer progression. Biomed Res Int 2015: 161508, 2015. PMID: 26064880. DOI: 10.1155/2015/161508

22 Bimonte S, Barbieri A, Palma G and Arra C: The role of morphine in animal models of human cancer: does morphine promote or inhibit the tumor growth? Biomed Res Int 2013: 258141, 2013. PMID: 26064880. DOI: 10.1155/2015/161508

23 Gupta K, Kshirsagar S, Chang L, Schwartz R, Law PY, Yee D and Hebbel RP: Morphine stimulates angiogenesis by activating proangiogenic and survival-promoting signaling and promotes breast tumor growth. Cancer Res 62(15): 4491-4498, 2002. PMID: 12154060.
24 Hartrick CT and Rozek RJ: Tapentadol in pain management: a mu-opioid receptor agonist and noradrenaline reuptake inhibitor. CNS Drugs 25(5): 359-370, 2011. PMID: 21476608. DOI: 10.2165/11589080-000000000-00000

25 Faria J, Barbosa J, Queirós O, Moreira R, Carvalho F and DinisOliveira RJ: Comparative study of the neurotoxicological effects of tramadol and tapentadol in SH-SY5Y cells. Toxicology 359: 1-10, 2016. PMID: 27317026. DOI: 10.1016/j.tox.2016.06.010

26 Justus CR, Leffler N, Ruiz-Echevarria M and Yang LV: In vitro cell migration and invasion assays. J Vis $\operatorname{Exp}$ (88): 51046, 2014. PMID: 24962652. DOI: 10.3791/51046

27 Braicu C, Gherman CD, Irimie A and Berindan-Neagoe I: Epigallocatechin-3-gallate (EGCG) inhibits cell proliferation and migratory behaviour of triple negative breast cancer cells. J Nanosci Nanotechnol 13(1): 632-637, 2013. PMID: 23646788.

Received June 24, 2019

Revised July 10, 2019

Accepted July 16, 2019 